\title{
Celebrity Endorsement, Price dan Customer Behavior terhadap Social Climber pada Generasi Melenial di Kota Denpasar
}

\author{
Desak Made Febri Purnama Sari ${ }^{1 *}$, Helmy Safitri ${ }^{2}$ \\ ${ }^{1 * 2)}$ Program Studi Manajemen, Fakultas Ekonomi dan Bisnis, Universitas Pendidikan \\ Nasional Denpasar \\ Jalan Bedugul No.39 Sidekarya Denpasar, Bali. 80224 \\ E-mail: dskfebripurnama@undiknas.ac.id ${ }^{\left.1^{*}\right)}$
}

\begin{abstract}
ABSTRAK
Penelitian ini bertujuan untuk mengetahui pengaruh celebrity endorsement, price, dan customer behavior terhadap social climber pada generasi milenial di Kota Denpasar. Populasi penelitian ini generasi milenial (1982-2000) yang berusia 19 tahun sampai 37 tahun di daerah Denpasar yang berjumlah 366.700 jiwa, penelitian menyebarkan kuesioner kepada 100 orang. Kuesioner sebagai alat ukur dengan skala likert. Penelitian menggunakan teknik kuantitatif. Metode analisis pada penelitian ini adalah analisis uji validitas, uji reliabilitas, uji asumsi klasik, dan uji analisis regresi linier berganda dengan bantuan aplikasi SPSS version 20.0. Dinyatakan bahwa celebrity endorsement, price, dan customer behavior merek berpengaruh positiif dan signifiikan secara parsial dan simultan terhadap social climber pada generasi milenial. Hasil pengujuan 54,7\% yang berarti bahwa variasi variable social climber mejelaskan bahwa ketiga varian variable independent celebrity endorsement, price dan customer behavior. Sedangkan sisanya $(100 \%-54,7 \%=45.3 \%)$ dijelaskan oleh sebab-sebab lain diluar model yaitu gaya hidup,lingkungan dan status sosial.
\end{abstract}

Kata Kunci: Celebrity Endorsement, Customer Behavior, Price dan Social Climer

\begin{abstract}
This study aims to determine the celebrity endorsement, price, and customer behavior of social climber in millennial generation in the city of Denpasar. The population of this study is millennial generation (1982 - 2000) aged 19 years - 37 years in the Denpasar area, amounting to 366,700 people, with a sample of 100 respondents. Data collection using a questionnaire with a Likert scale measurement tool. The type of data used in this study is quantitative data. The data analysis method used in this study uses validity test, reliability test, classic assumption test, and multiple linear regression analysis test using the SPSS version 20.0 application. The results of this study state that celebrity endorsement, price and customer behavior have a positive and significant effect partially and simultaneously on social climber on millennial generation in the city of Denpasar. This means that $54.7 \%$ of the variation of social climber variables can be explained by variations of the three independent celebrity endorsement variables, price and customer behavior. While the rest $(100 \%-54.7 \%=45.3 \%)$ is explained by other causes outside the model, namely lifestyle, environment and social status.
\end{abstract}

Keywords: Celebrity Endorsement, Customer Behavior, Price and Social Climber

\section{PENDAHULUAN}

Pergaulan yang sangat luas dan pola hidup yang keras diperkotaan menjadikan tolak ukur yang tajam untuk setiap orang agar mereka dapat begaul, berbaur dan diterima dimasyarakat. Penelitian terdahulu Wahyu Ria Lestari (2017). Pew Research Center 
menyatakan lingkungan yang dikatakan generasi milenial yang memiliki batasan tahun kelahiran 1982-2000 mulai usia 19 tahun sampai 37 tahun pada 2018 akan dianggap sebagai generasi milenial yang menjadikan adanya pengelompokan status sosial rendah, sedang atau tinggi.Sonwalkar dkk (2011), endorser adalah sebuah bentuk komunikasi dimana seorang selebriti bertindak sebagai juru bicara dari sebuah produk atau merek tertentu. Celebrity Endorser adalah orang-orang terkenal yang dapat mempengaruhi karena prestasinya, karena untuk melakukan hal ini selebritis mempunyai kekuatan karena mereka menjadi idola banyak orang (Wiryawan dan Pratiwi: 2009).

Menurut Kotler dan Amstrong (2012), bahwa harga dapat didefinisikan secara sempit sebagai jumlah uang yang ditagihkan untuk suatu produk atau jasa yang ada . Menurut Hasan (2013), perilaku konsumen adalah studi proses yang terlibat ketika individu atau kelompok memiliih, membeli, menggunakan, atau mengatur produk dan jasa. Menggunakan media sosial membuat generasi milenial mendapatkan informasi mengenai gaya hidup mereka lewat celebrity favoritnya dan mengikuti gaya tersebut dengan cara mempublikasikan kehidupan gaya hidup mereka, untuk mendapat simpati atau sorotan. Menurut Jayanti (2015), social climber adalah hal yang dapat diusahakan untuk mendapatkan posisi yang lebih kuat dalam sebuah partisipasi baik secara individual maupun kelompok. Salah satu penilaian dukungan celebrity terlihat dari popularitas celebrity dan itu dapat ditentukan oleh berapa banyak penggemar yang dimiliki oleh dukungan celebrity serta dilihat dari jumlah pengikut celebrity itu karena berapa banyak penggemar yang ada, sehingga akan ada kemungkinan untuk menambah dan mempengaruhi jumlah kebiasaan pembeli dari para pengikut celebrity tersebut (Sari \& Yulianti, 2019).

Kedinamisan trend fashion yang terus bergerak dengan perkembangan teknologi menjadi pendorong perilaku iri, yang dimaksud adalah tiap invidu selalu berusaha memenuhi kebutuhan yang tidak secara primer lagi namun skunder dan cenderung melakukan konsumsi tidak sesuai kebutuhan. Perilaku social climbing yang seperti ini akan menimbulkan dampak negatif dalam masyarakat di mana masyarakat akan memberikan reaksi yang kurang baik, reaksi seperti itu muncul akibat masyarakat tidak menyukai perilaku yang tidak baik untuk diikuti karena tidak bisa menjadi diri sendiri dan apa adanya. Karakteristik yang terbentuk pada generasi milenial adalah kecanduan internet, percaya diri dan harga diri tinggi dan lebih terbuka dan bertoleransi terhadap perubahan (Kilber, et al, 2014). Yuswohady dalam artikel Milennial Trends (2016), menyatakan bahwa generasi milenial (Millennial Generation) adalah generasi yang dari lahir dalam rentang waktu awal tahun 1982 hingga tahun 2000. Terbentuknya karakteristik pada generasi millenial yang tidak dapat dihindari 
adalah kecanduan internet dan kemudahan akses internet (Kilber, et al, 2014). Perubahan gaya hidup pada generasi milenial di Kota Denpasar menjadi keunikan dan tantangan penulis yang menarik melakukan penelitian yang lebih mendalam mengenai pengaruh dari terjadinya social climber pada generasi milenial. Rumusan permasalahan yaitu: 1) Bagaimana pengaruh Celebrity Endorsement terhadap di Kota Denpasar?, 2) Bagaimana pengaruh Price terhadap Social Climber di Kota Denpasar?, 3) Bagaimana pengaruh Customer Behavior terhadap Social Climber di Kota Denpasar? Dan 4) Bagaimana pengaruh Celebrity Endorsement, Price dan Customer Behavior terhadap Social Climber di Kota Denpasar?

Celebrity endorser merupakan kegiatan yang dilakukan oleh individu promosi produk dengan artis sebagai tokoh pengiklannya (Handi Chandra, 2010). Kegiatan tersebut tersampaikan melalui iklan baik pada televisi, koran, majalah, brosur, poster dan media sosial terdapat seseorang yang mewakili penyampian informasi suatu produk dan serta berusaha membujuk individu untuk membeli produk tersebut.

Kotler dan Keller (2009), mendefinisikan harga sebagai satu unsur bauran pemasaran yang dapat menghasilkan pendapatan sedangkan yang lainnya menghasilkan biaya-biaya. Menurut Kotler (2009), harga merupakan nilai yang dipertukarkan konsumen untuk mendapatkan suatu manfaat atas pengkonsumsian, penggunaan atau kepemilikan barang atau jasa. Biasanya seorang penjual menetapkan harga berdasarkan kombinasi barang secara dan beberapa jasa lain serta keuntungan yang memuaskan yang dapat dirasakan konsumen.

Schiffman dan Kanuk dalam Sumarwan, dkk (2012), bahwa an perilaku konsumen sebagai tindakan yang langsung terlibat dalam mendapatkan, mengonsumsi dan menghabiskan produk atau jasa, termasuk proses keputusan yang mendahului dan mengikuti tindakan yang ada. Menurut Sunyoto (2012), perilaku konsumen (customer behavior) dapat diartikan sebagai kegiatan individu yang secara langsung terlibat dalam mendapatkan dan mempergunakan barang-barang atau jasa termasuk didalamnya proses pengambilan keputusan pada persiapan dalam penentuan kegiatan-kegiatan tersebut

Menurut Jayanti (2015), social climber adalah hal yang dapat diusahakan untuk mendapatkan posisi yang lebih kuat dalam sebuah partisipasi baik secara individual maupun kelompok. Wahyu (2017), dalam penelitiannya menyatakan bahwa perilaku social climber di kalangan generasi milenial dengan menciptakan suatu perilaku dalam media sosial untuk mengejar gaya hidup yang mewah. 


\section{Kerangka Berpikir}
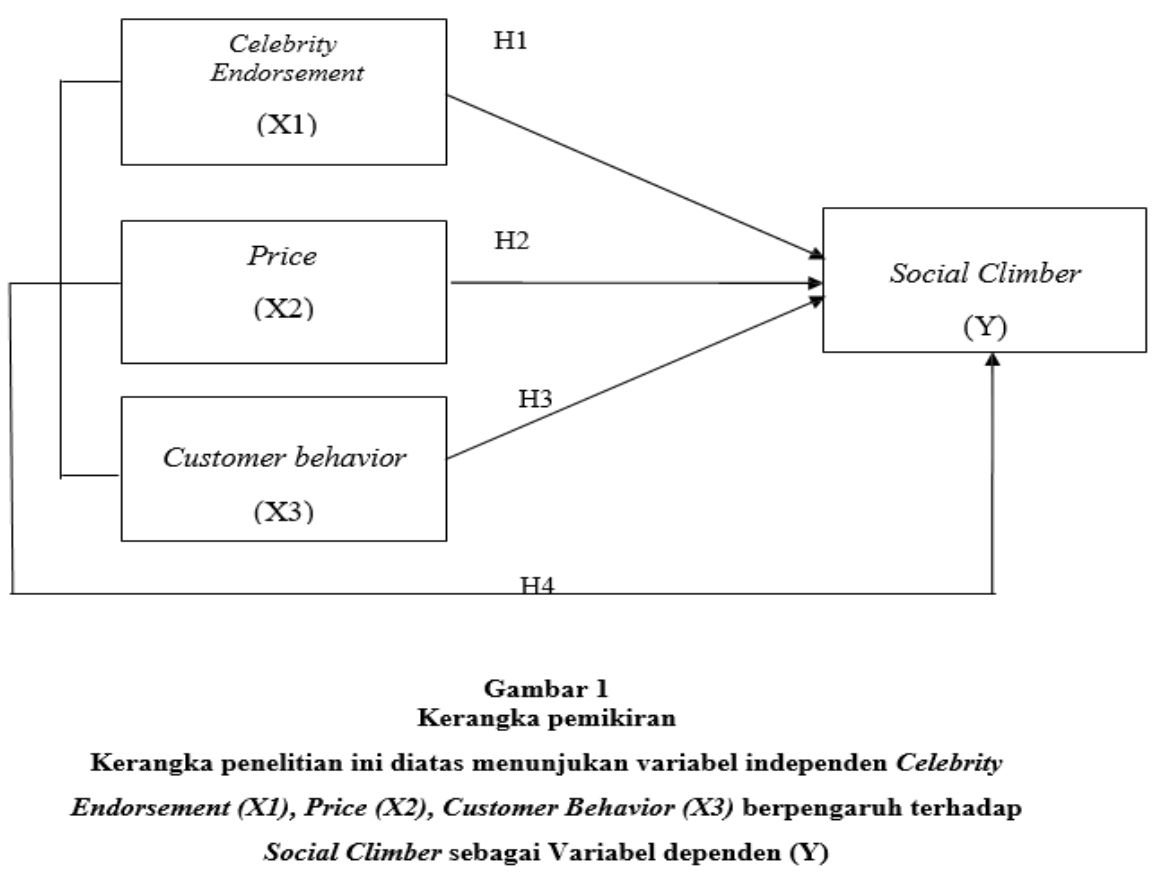

\section{Hipotesis}

Dadan Abdul Aziz Mubarak (2016) menyatakan bila pelayanan yang diberikan seorang celebrity dalam endorsement sangat menarik, maka mudah untuk pelanggan akan terdorong untuk panjat social (social climber) yang dimana muncul kecenderung untuk mengikuti apa yang selebgram tersebut gunakan. Celebrity Endorsement berpengaruh nilai positif dan signifikan terhadap Social Climber. Sehingga dapat dirumusakan hipotesis H1.

H1: Celebrity Endorsement (X1) berpengaruh positif dan signifikan terhadap Social Climber $(Y)$.

Hamni Fadlilah (2018) menyatakan harga yang diberikan dalam suatu produk bukan menjadikan masalah seseorang untuk membeli suatu produk demi melakukan kepanjatan sosialannya (social climber). Price berpengaruh positif dan signifikan terhadap Social Climber. Sehingga dapat dirumusakan hipotesis $\mathrm{H} 2$.

H2: Price (X2) berpengaruh positif dan signifikan terhadap Social Climber (Y).

Suhardiman (2018) menyatakan tingkat perilaku konsumen dapat diasumsikan sebagai melakukan panjat sosial (social climber), pada saat itu konsumen akan merasa produk tersebut sangat dibutuhkan dan akan selalu puas dengan apa yang dilakukan demi panjat sosial. Penelitian menunjukan bahwa Customer Behavior berpengaruh positif dan signifikan terhadap Social Climber. Sehingga dapat dirumusakan hipotesis H3. 
H3: Customer Behavior (X3) berpengaruh positif dan signifikan terhadap Social Climber (Y).

Dian nursita (2019) menyatakan jasa pelayanan yang diberikan seorang celebrity dalam endorsement sangat menarik dimana cenderung ingin mengikuti apa yang celebrity tersebut gunakan, harga yang diberikan untuk membeli suatu produk, serta tingkat perilaku konsumen yang selalu merasa produk tersebut sangat dibutuhkan, maka bukan suatu hal yang sulit sesorang akan melakukan panjat sosial (social climber). Penelitian menunjukan bahwa Celebrity Endorsement, Price, dan Customer Behavior berpengaruh positif dan signifikan terhadap Social Climber. Sehingga dapat dirumusakan hipotesis H4.

H4: Celebrity Endorsement, Price, dan Customer Behavior berpengaruh positif dan signifikan terhadap Social Climber

\section{METODE PENELITIAN}

Penelitian berlokasi dikota denpasar. Populasi adalah generasii milenial di Kota Denpasar yang berjumlah 366.700 jiwa, dengan sampel berjumlah 100 responden melalui penyebaran kuisioner. Teknik penentuan sampel metode accidental sampling dengan rumus Slovin, metode kuantitatif, data primer dan data skunder. Teknik analisis data yaitu regresi linier berganda. Uji intrumen penelitian melakukan uji validitas Sugiyono (2011), item pernyataan dalam kuisioner disebut valid jika butir pernyataan memiliki $r$ hitung $>r$ table $=$ 0,30 dan uji reliabilitas suatu konstruk atau variabel dikatakan reliabel jika memberikan nilai Cronbach Alpha > 0,6 (Imam Ghozali, 2011:48). Teknik analisis data yang digunakan analisis regresi linier berganda digunakan untuk mengetahui ada tidaknya pengaruh Celebrity Endorsement, Price, dan Customer Behavior terhadap Social Climber pada generasi mileniali di Kota Denpasar. Dalam penelitian ini variabel independennya adalah Celebrity Endorsement (X1), Price (X2), dan Customer Behavior (X3). Sedangkan variabel dependennya adalah Social Climber (Y). Uji Asumsi Klasik yang terdiri dari Uji Multikolinearitas dengan meilihat nilai tolerance dan VIF, uji normalitas dengan melihat nilai kolmongorov-smirnov dengan tingkat signifikan 0,05 dan uji heterokedastisitas yaitu dengan Uji Glejser.

Uji Signifikan Parsial (Uji t) dengan dasar pengambilan keputusan uji t sebagai berikut: apabila nilai probabilitas signifikan > 0,05 maka hipotesis ditolak. Karena variabel independen tidak berpengaruh terhadap variabel dependen serta apabila nilai probabilitas signifikan $<$ 0,05 maka hipotesis diterima. Uji Signifikan simultan (Uji F) dengan dasar pengambilan keputusan menggunakan probilitas signifikansi yaitu sebagai berikut: apabila 
probabilitas signifikansi $>0,05$ maka $\mathrm{H} 0$ diterima dan $\mathrm{Ha}$ dan apabila probabilitas signifikansi < 0,05 maka $\mathrm{H} 0$ ditolak dan $\mathrm{Ha}_{\mathrm{a}}$ diterima. serta yang terakhir melakukan uji koefisien determinasi menyatakan bahwa koefisien determinasi pada intinya mengukur seberapa jauh kemampuan model dalam menerangkan variasi variabel independen (Ghozali, 2013).

\section{HASIL DAN PEMBAHASAN}

Indikator variable pada penelitian ini yaitu variabel Celebrity Endorsement, Price, dan Customer Behavior terhadap Social Climber valid dengan memiliki nilai koefisien korelasi lebih dari 0,30. Begitu juga dengan hasil uji reliable, instrument dalam penelitian variabelvariabel penelitian dikatakan reliable dengan variabel memiliki nilai Alpha lebih besar 0,60 yang diperoleh dari hasil uji. Berdasarkan uji normalitas dengan menggunakan One-Sample Kolmogorov- Smirnov tersebut menunjukan bahwa besarnya nilai Kolmogorov-Smirnov adalah sebesar 0,595 yaitu lebih besar dari derajat keyakinan $(\alpha)$ Kolmogorov-Smirnov test sebesar 0,05 yang menunjukan bahwa data terdistribusi secara normal, sehingga dapat disimpulkan bahwa model memenuhi asumsi normalitas. Hasil uji multikolinearitas ditunjukkan bahwa tidak ada variabel bebas yang memiliki nilai tolerance celebrity endorsement 0,644 , price 0,868 , customer behavior $0,707>0,10$, begitu juga dengan hasil perhitungan nilai VIF, tidak ada yang memiliki nilai VIF tolerance celebrity endorsement1.553, price 1.152, customer behavior $1.415<10$. Hal ini berarti bahwa pada model regresi yang dibuat tidak terdapat gejala multikolinearitas. Hasil uji heteroskedasitas ditunjukkan bahwa masing-masing model memiliki nilai signifikansi lebih besar dari 0,05 celebrity endorsement 0,643 , price 0,266 , customer behavior 0,764 .

Tabel 1. Hasil Uji Analisis Regresi Linear Berganda

\begin{tabular}{|c|c|c|c|c|c|c|c|c|}
\hline \multirow[t]{2}{*}{ Model } & \multicolumn{2}{|c|}{$\begin{array}{l}\text { Unstandardized } \\
\text { Coefficients }\end{array}$} & \multirow{2}{*}{$\begin{array}{c}\begin{array}{c}\text { Standardized } \\
\text { Coefficients }\end{array} \\
\text { Beta }\end{array}$} & \multirow[t]{2}{*}{$\mathrm{t}$} & \multirow[t]{2}{*}{ Sig. } & \multicolumn{2}{|c|}{$\begin{array}{l}\text { Collinearity } \\
\text { Statistics }\end{array}$} & \\
\hline & B & Std. Error & & & & Tolerance & VIF & \\
\hline (Constant) & .628 & 1.057 & & .594 & .554 & & & \\
\hline $\begin{array}{l}\text { Celebrity } \\
\text { Endorsement }\end{array}$ & .397 & .080 & .417 & 4.948 & .000 & .644 & 1.553 & Diterima \\
\hline Price & .227 & .054 & .302 & 4.169 & .000 & .868 & 1.152 & Diterima \\
\hline Customer Behavior & .117 & .038 & .247 & 3.072 & .003 & .707 & 1.415 & Diterima \\
\hline
\end{tabular}


$\mathrm{Y}=0.628+0.397 \mathrm{X} 1+0.227 \mathrm{X} 2+0.117 \mathrm{X} 3+\mathrm{e}$

\section{H1: Celebrity Endorsement (X1) berpengaruh positif dan signifikan terhadap} Social Climber (Y).

Penelitian ini membuktikan pada uji hipotesis pertama bahwa celebrity endorsement berpengaruh positif dan signifikan secara parsial terhadap social climber pada generasi milenial. Dalam hal ini berarti semakin terkenal artis yang digunakan untuk endorsement suatu produk maka akan meningkatkan status sosial pemakai produk tersebut. Begitu juga sebaliknya semakin kurang terkenal artis yang digunakan untuk endorsement suatu produk maka akan tidak akan mampu meningkatkan status sosial pemakai produk tersebut.

\section{H2: Price (X2) berpengaruh positif dan signifikan terhadap Social Climber (Y)}

Dalam penelitian ini membuktikan pada uji hipotesis pertama bahwa price berpengaruh positif dan signifikan secara parsial terhadap social climber pada generasi milenial. Dalam hal ini berarti semakin tinggi harga dari suatu produk maka akan meningkatkan status sosial pemakai produk tersebut. Begitu juga sebaliknya semakin rendah harga dari suatu produk maka tidak akan mampu meningkatkan status sosial pemakai produk tersebut. Hasil penelitian tersebut menunjukkan bahwa variabel Price berpengaruh positif signifikan terhadap Social Climber.

\section{H3: Customer Behavior (X3) berpengaruh positif dan signifikan terhadap Social Climber} (Y).

Kesimpulan dalam penelitian ini membuktikan pada uji hipotesis pertama bahwa customer behavior berpengaruh positif dan signifikan secara parsial terhadap social climber pada generasi milenial. Dalam hal ini berarti semakin tinggi customer behavior generasi milenial maka akan meningkatkan social climber pada generasi milenial. Begitu juga sebaliknya semakin rendah customer behavior pada suatu produk maka akan tidak akan meningkatkan social climber pada generasi milenial.

H4: Celebrity Endorsement, Price, dan Customer Behavior berpengaruh positif dan signifikan terhadap Social Climber.

Kesimpulan dalam penelitian ini membuktikan pada uji hipotesis keempat bahwa celebrity endorsement, price dan customer behavior berpengaruh signifikan secara bersama-sama (simultan) terhadap social climber pada generasi milenial. Dalam hal ini berarti bahwa semakin baik celebrity endorsement, price dan customer behavior maka semakin meningkat pula celebrity endorsement pada generasi milenial. Begitu pula sebaliknya, apabila celebrity endorsement, price dan customer behavior menurun maka social climber pada generasi milenial juga akan menurun. 
Tabel 2. Hasil Uji Koefisien Determinasi

\begin{tabular}{llllll}
\hline Model & $\mathrm{R}$ & R Square & $\begin{array}{l}\text { Adjusted } \\
\text { Square }\end{array}$ & $\mathrm{R}$ & Std. Error of the Estimate \\
\hline 1 & $.749^{\mathrm{a}}$ & .561 & .547 & 1.335
\end{tabular}

Sumber: Data diolah, 2019

Besarnya $\left(\mathrm{R}^{2}\right)$ adalah 0,547 , hal ini berarti $54,7 \%$ variasi variable social climber dapat dijelaskan oleh variasi dari ketiga variable independent celebrity endorsement, price dan customer behavior mengartikan bahwa ketiga variabel memberikan pengaruh yang cukup besar diatas $50 \%$ sehingga perhatian akan hal tersebut tidak hanya lagi sebatas perilaku yang dilakukan sebagaiman masyarakat namun telah masuk ke pola pikir dan merubah tindakan demin pencapaian serata sosial atau social climber pada lingkunngan. Dapat dikatakan pula celebrity endorsement, price dan customer behavior, social climber kini menjadi dapat dilakukan oleh siapa saja dengan karakteristik individu yang beragam. Sedangkan sisanya $(100 \%-54,7 \%=45.3 \%)$ dijelaskan oleh sebab-sebab lain diluar model yaitu gaya hidup,lingkungan yang dimana perubahan akan lingkungan bergerak secara dinamis dan tidak dapat dihindari, mendukung adanya pergeseran paradigma masyarakat sebagai konsumen yang cenderung memperlihatkan diri dan berlomba untuk menjadi pusat perhatian dan status sosial yang kini menjadi tujuan yang melengkapi gaya hidup untuk dapat diakui di lingkungan.

\section{KESIMPULAN}

Celebrity endorsement memiliki pengaruh yang positif dan signifikan terhadap social climber. Ini berarti bahwa semakin terkenal artis yang digunakan untuk endorsement produk tas maka akan meningkatkan social climber pada generasi milenial di Kota Denpasar. Price memiliki pengaruh yang positif dan signifikan terhadap social climber. ini berarti bahwa semakin tinggi harga dari produk tas maka akan meningkatkan social climber pada generasi milenial di Kota Denpasar.

Customer behavior memiliki pengaruh yang positif dan signifikan terhadap social climber. Ini berarti bahwa semakin tinggi customer behavior pada produk tas maka akan meningkatkan social climber pada generasi milenial di Kota Denpasar.

Celebrity endorsement, price dan customer behavior secara bersama-sama memiliki pengaruh yang signifikan terhadap social climber. Ini berarti bahwa semakin baik 
celebrity endorsement, price dan customer behavior pada produk tas maka semakin meningkat pula celebrity endorsement pada generasi milenial Kota Denpasar.

Celebrity endorsement, price dan customer behavior terhadap social climber.

Diketahui pada penelitian ini celebrity endorsement dengan nilai koefisien 0,417 memiliki pengaruh yang paling kuat dibandingkan price sebesar 0,302 dan customer behavior sebesar 0,247. Hal ini karena dengan melakukan endorsement menggunakan artis terkenal maka kana meningkatkan status sosial pemakai produk tersebut.

Implikasi dari hasil penelitian ketiga variable independent celebrity endorsement, price dan customer behavior mengartikan bahwa ketiga variabel memberikan pengaruh yang cukup besar diatas $50 \%$ sehingga perhatian akan hal tersebut tidak hanya lagi sebatas perilaku yang dilakukan sebagaiman masyarakat namun telah masuk kepola pikir dan merubah tindakan demi pencapaian serata sosial atau social climber pada lingkunngan. Dapat dikatakan pula celebrity endorsement, price dan customer behavior, social climber kini menjadi dapat dilakukan oleh siapa saja dengan karakteristik individu yang beragam. Pergerersan paradigma ini dapat membantu melihat sudut pandang yang berbeda dengan melihat perilaku generasi melenial kota Denpasar sebagai tempat berkumpulnya kaum muda yang energik yang tentu menjadi perhatian khusus pula untuk tetap memiliki jati diri dimana kota denpasar tetap berlandaskan budaya. Keterbatasan penelitian ini adalah dimana lokasi penelitian hanya dikota Denpasar tidak mewakili seluruh Bali.

Saran hasil penelitian dimana suatu barang seperti tas jangan hanya karena untuk meningkatkan status sosial akan tetapi melihat dari fungsi barang tersebut, serta para produsen tas hendaknya dalam mempromosikan produk tas mereka bekerja sama dengan artis terkenal untuk melakukan celebrity endorsement serta memberikan harga yang sesuai dengan kualitas dari bahan serta desain yang digunakan.

\section{REFERENSI}

Ayu Puspita A, D. (2013). Pengaruh Gaya Hidup, Fitur, dan Harga terhadap Keputusan Pembelian Blackberry Curve 9300. Jurnal Ilmu Manajemen (JIM), l(1).

Hansudoh, S. A. (2012). Pengaruh Celebrity Endorsement terhadap Purchase Intention Melalui Perceived Value Pada Produk Top Coffe di Surabaya. Jurnal Ilmiah Mahasiswa Manajemen, 1(5), 1-7.

Harga, P., Produk, U., Com, T., Bisnis, P. M., Manajemen, P. S., Petra, U. K., \& Siwalankerto, J. (2017). Keamanan terhadap Keputusan Pembelian Secara Online di Tokopedia.Com. Jurnal Manajemen Bisnis, 5(1). Retrieved from http://publication.petra.ac.id/index.php/manajemen- bisnis/article/view/5227/4814 
Jayanti, N. A. (2015). Komunikasi Kelompok "Social Climber "Pada Kelompok Pergaulan di Surabaya Townsquare (Sutos). Jurnal E-Komunikasi Program Studi Ilmu Komunikasi Universitas Kristen Petra, 3(2), 1-12.

Jayanti, R. D. (2015). Pengaruh Harga dan Kepercayaan terhadap Keputusan Pembelian secara Online (Studi Kasus pada Harapan Maulina Hijab Jombang). STIE PGRI Dewantara Jombang, 10(1), 13-27.

Kartikasari, D., Arifin, Z., \& Hidayat, K. (2013). Pengaruh Perilaku Konsumen terhadap Keputusan Pembelian. Jurnal Administrasi Bisnis, 3(2), 1-8. Retrieved fromhttp://administrasibisnis.studentjournal.ub.ac.id/index.php/jab/ article/view/135.

Kresnardi, V. C., Program, A., Pemasaran, M., Ekonomi, F., Petra, U. K., \& Siwalankerto, J. (2017). Pengaruh Celebrity Endorsement terhadap Buying Intention melalui Self-Brand Connection pada Dum Dum Thai Drinks Surabaya. Jurnal Manajamen Pemasaran, 4(1).

Retrieved

from

http://publication.petra.ac.id/index.php/manajemenpemasaran/article/view/5139/4732

Lanongbuka, M. C. (2018). Pengaruh Celebrity Endorsements Terhadap Niat Pembelian Konsumen (Studi Penggunaan Karin Novilda Sebagai Bintang Iklan Dalam Instagram) (Universitas Atma Jaya Yogyakarta). Retrieved from http://e-journal.uajy.ac.id/16263/

Man Mubarak, N. ', Fauzi, A., Inggang, D. H., \& Nuralam, P. (2018). Pengaruh Celebrity Endorser pada Media Sosial Instagram terhadap Keputusan Pembelian (Survei Online pada Konsumen Produk Erigo Jakarta melalui Instagram). Jurnal Administrasi Bisnis, 62(1), 18-25.

Mubarok, D. A. A. (2016a). Pengaruh Celebrity Endorsement terhadap Minat Beli Konsumen. Jurnal Indonesia Membangun. Jurnal Indonesia Membangun, 3(1), 6176. Retrieved from jurnal inaba.hol.es/index.php/JIM/article/viewFile/77/82\%0D

Mubarok, D. A. A. (2016b). Pengaruh Celebrity Endorsement terhadap Minat Beli Konsumen. Jurnal Indonesia Membangun, 3(1), 61-76. Retrieved from https://jurnal.inaba.ac.id/index.php/JIM/article/view/77/72\%0D

Nasution, H. F. (2018). Pengaruh Kemudahan dan Harga terhadap Keputusan Pembelian Produk Pakaian Secara Online (Studi Kasus Mahasiswa Belanja Online pada Febi Iain Padangsidimpuan). At-Tijaroh: Jurnal Ilmu Manajemen Dan Bisnis Islam, 4(1), 26. https://doi.org/10.24952/tijaroh.v4i1.1082

Nursita, D. (2019). Social Climber sebagai Gaya Hidup Mahasiswa. Jurnal Psikologi, 1-15. Retrieved from eprints.ums.ac.id/73410/1/NASKAH PUBLIKASI.pdf\%0D

Rafiz, F. M. (2016). Keputusan Pembelian Mobil Merek Daihatsu (Studi pada Konsumen Kendaraan Daihatsu di PT. Jolo Abadi Authorized Daihatsu Dealer Malang). Jurnal Administrasi Bisnis, 39(2), 105-111.

Rahmadani, R., \& Ananda, F. (2018). Keputusan Pembelian di Online Shop Tokopedia. Jurnal Ilmu Ekonomi. Retrieved from https://osf.io/preprints/inarxi v/as9wc\%0A

Saputri, M. E. (2016). Pengaruh Perilaku Konsumen terhadap Pembelian Online Produk Fashion pada Zalora Indonesia. Jurnal Sosioteknologi, 15(2), 291- 297. Retrieved from https://doi.org/10.5614/sostek.itbj.2016.15.02.11

Sari, D. M. F. P., \& Yulianti, N. M. D. R. (2019). Celebrity Endorsement, Electronic Word of Mouth and Trust Brand on Buying Habits. International Journal of Social Sciences and Humanities, 3(1), 82-90. Retrieved from https://doi.org/10.29332/ijssh.v3n1.261

Suhardiman. (2018). Pengaruh Perilaku Konsumen terhadap Keputusan Pembelian Kartu Internet Axis pada Mahasiswa Fakultas Ekonomi dan Ilmu Sosial (Universitas Islam Negeri Sultan Syarif Kasim Riau). Retrieved from http://repository.uinsuska.ac.id/13058/3/3. ABSTRAK_2018488MEN.pdf

Wisnumurti, R. (2015). Pengaruh Harga, Kualitas Pelayanan dan Persepsi Resiko terhadap Keputusan Pembelian Pakaian Atasan Wanita yang Dijual secara Online melalui Grup 
Blackberry Messenger (studi pada girls outfit project shop). Jurnal Pendidikan Tata Niaga, 3(2), 1-17. Retrieved from http://jurnalmahasiswa.unesa.ac.id/index.php/jptn/article/view/12040. 